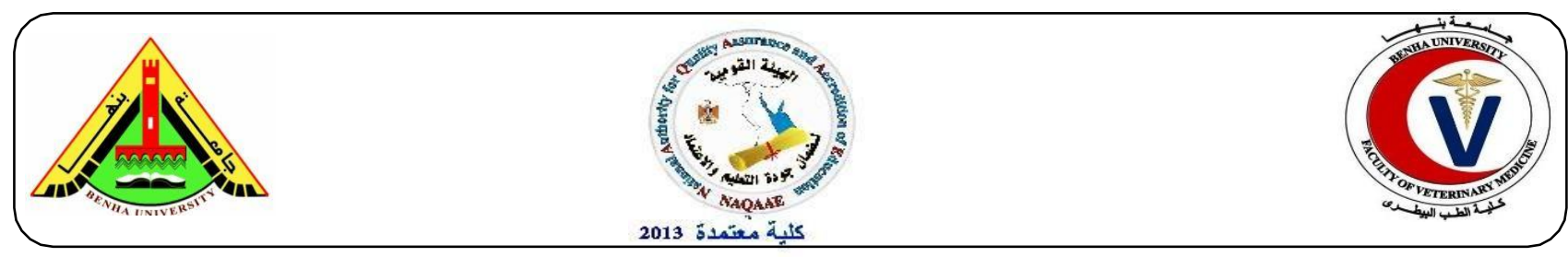

\title{
Brain anatomy and Histology in Teleosts
}

\section{(Review Article)}

Mona Nasr Abdelnaeim Hussein ${ }^{1,2}$ and Xiaojuan Cao ${ }^{* 1}$

${ }^{l}$ College of Fisheries, Key Lab of Agricultural Animal Genetics, Breeding, and Reproduction of Ministry of Education, Huazhong Agricultural University, Wuhan, Hubei 430070, China.

${ }^{2}$ Department of Histology and Cytology, Faculty of Veterinary Medicine, Benha University, Egypt.

Corresponding author*: Xiaojuan Cao Mail: caoxiaojuan@mail.hzau.edu.cn

\section{ABSTRACT}

The anatomical and histological observations of the brain in fishes differ among species, but they resemble each others in the number of brain compartments, and it is necessary to characterize well the anatomical and histological observations in the brain of each particular kind of fishes for doing further subjects in the brain. Five brain divisions usually observed which are from cranial to caudal; telencephalon or forebrain (contain 2 olfactory lobes and cerebrum), diencephalon (contain epithalamus, thalamus and hypothalamus), mesencephalon or midbrain (contain 2 optic lobes which are connected internally with torus longitudinalis and medially with the torus semi-circularis, and optic tegmentum), metencephalon or hindbrain (cerebellum) and myelencephalon or brain stem (medulla oblongata). The ventricular organization composed of the olfactory, lateral, the third, the tectal and the fourth ventricles. The adult neurogenesis process is usually observed in the fish brain, unlike mammal's brain. The adult neurogenesis usually detected in cerebellum, optic lobe, and telencephalon.

Key words: brain, anatomy, histology, teleosts.

(BVMJ-35(2):436-463,2018)

\section{INTRODUCTION}

The teleost fish constitute two great mathematical group: the action-pterygians or ray-finned fishes, which contain most bony fishes, and the sarco-pterygians or lobe-finned fishes, which are only seven or eight kinds of fish species.

\section{REVIEW OF LITERATURE:}

\subsection{Embryogenesis}

The brain and the spinal cord formed by process named neurulation in which the neural tube in the embryo their walls thickened and for the central nervous system and the hollow tube formed during this process form the ventricular system. In ray-finned (Actinopterygian) fishes some parts of the brain don't reach complete maturation like other fishes (González and Northcutt, 2011). Actinopterygian fish are classified into several kinds in accordance to developmental changes and structural differences in their brain compartments. However, some brain compartment remains similar between these fishes and other kinds of vertebrates (Butler, 
2011).

Brain anatomy and Histology in Teleosts (Review Article)

The telencephalon in actinopterygian fishes protrusion from the pallium except for the cladistians, in which thickening in the walls usually occurs with this protrusion development (Nieuwenhuys, 2011). In Acipenser fish, this process usually detected at the fourth day of old. The epiphysis begins development during the first days of larvae, while other hypothalamic parts developed later.

The mesencephalon usually keeps its embryonic shape which is two compartments tectal and tegmental portions; the tegmental poretion usually begins in development before tectal portion. In zebrafish embryos at $26 \mathrm{hpf}$, transverse sections showed that, the torus semicircularis (TS) develops internally and medially over the tegmentum. Afterward, proliferation becomes restricted to the intermediate portion between the optic tectum (OT) and the TS. It gradually extends during the development and constitutes the peripheral midbrain layer (PML) between the OT and TS (Recher et al., 2013b).

Two laterally projected compartments form the cerebellum and later they fuse together and form the ventricular cavity. At first the corpus cerebelli begins in development then followed directly by the valvula cerebella.

The torus longiudinalis deign growth with granular eminences and before optic tectum and cerebellar crest development (Candal et al., 2005) in trout and medaka fishes, (Bäuerle and Rahmann, 1993) in Oreochromis mossambicus, (Toyoda and Uematsu, 1994) in Pagrus major (red seabream) and (Sprague et al., 2001; Wullimann and Knipp, 2000) in zebrafish.

The hindbrain in fish composed of the pons, cerebellum, and myelencephalon. In the embryos a dorsal protrusion from the neural tube wall and the alar plates, forms the medulla 2.2. Adult brain anatomy (Fig. 1) oblongata. A choroidal plexus which is lining the ventricular systems is responsible for cerebro-spinal fluid formation in fish (Redzic et al., 2005).

Laterally the ventricular system develops which later form all kinds of glial and neuronal cells for formation of various brain regions (Butler and Hodos, 2005). In most vertebrates, the ventricular system extends laterally within the telencephalic hemispheres, forming the lateral ventricle. This ventricle connected with the tectal ventricle which in turn connects it to the third ventricle.

The cerebral aqueduct is a thin canal connecting the third ventricle to the fourth ventricle in the hindbrain (Butler and Hodos, 2005). The fourth ventricle extends backward toward the central canal of the spinal cord. The brain of Dolloidraco fish has many unusual characters in their ventricular system, like presence of some sub-ependymal protrusions, well developed circumventricular organs, a ventricle in the corpus cerebellum and subarachnoid cisterns (Eastman and Lannoo, 2003).

In larvae at the age of 15-days, there was a connection between lateral ventricle and the preoptic recess, which is connected to the third ventricle in the diencephalon via the interventricular foramen. The cerebral aqueduct lies between the cerebellar ventricle and the tectal ventricle. The fourth ventricle was visualized in the center of the medulla oblongata and continued as the central canal into the spinal cord (Tavighi et al., 2015). While in action-pterygian fishes, due to the eversion of the telencephalon during embryonic growth, the olfactory ventricle and lateral ventricle together formed a T-shaped telencephalic ventricle (Northcutt and Jr, 1980; Nieuwenhuys, 1998). 


\subsubsection{Telencephalon}

The olfactory bulb of Barbus meridionalis, Carassius auratus, and Cyprinus carpio fishes was a spherical or oval and joined to the telencephalon by a very long olfactory tract. While in Salmo- gairdneri, it was a pyriform structure (Alonso et al., 1989). In Eleginops maclovinus, the olfactory bulbs were large and about half the volume of the telencephalic lobes (Eastman and Lannoo, 2008).

\subsubsection{Diencephalon}

The diencephalon formed from the epithalamus, thalamus (posterior tuberculum, ventral thalamus, and dorsal thalamus), preoptic area, hypothalamus, synencephalon, some optic nuclei and the pretectum (Butler and Northcutt, 1993). The thalamus of teleosts composed from the thalamus proper, the habenula, and the prethalamus (Mueller and Wullimann, 2016). Some pre-thalamic structures are the intermediate, the ventromedial, and the ventro-lateral thalamic nuclei were observed only in amphibians (Rupp and Northcutt, 1998; Butler and Northcutt, 1993; Neary and Northcutt, 2010).

The thalamus is located dorsolateral to the hypothalamus, and rostral to the tegmentum of the mesencephalon. The epi-thalamus is composed of the habenula and its commissure. The synencephalon is the region in between the optic tegmentum and the thalamus (Puelles and Rubenstein, 1993).

\subsubsection{Mesencephalon}

The mesencephalon of the gilthead seabream contains optic tectum dorsally and optic tegmentum ventrally. The dorsal tectum evaginates into two bilateral lobes attached dorsally with the tectal commissure and is composed of the optic tectum and the torus longitudinalis. The tegmentum and is related dorsally to the valvula cerebelli, related laterally to the optic tectum and ventrally is related to the inferior lobe of the hypothalamus.
rests (Review Arte) In most fishes, the optic tectum composed of; the superficial white and gray zone (SWGZ), the central zone $(\mathrm{CZ})$, the deep white zone (DWZ) and the periventricular gray zone (PGZ) (Eastman and Lannoo, 2001).

\subsubsection{Hindbrain and Myelencephalon}

The cerebellum of Otothyris is lower in size in comparison with Gymnotocinclus (Rosa and Rosa, 2014). The medulla oblongata contains anterior and posterior parts both are ovoid in shape but the anterior one is slightly larger in size than the posterior part. The vagal lobe formed from two lobes cylindrical in shape. It located posterior to the facial lobe and dorsal to the medulla oblongata. The facial lobe is enclosed ventrally by the medulla oblongata, anteriorly by the corpus cerebelli, posteriorly by the vagal lobe. The two facial lobes do not attach each others, inspite the two facial lobes attached anteriorly with the corpus cerebelli (Abrahão et al., 2015). The medulla oblongata formed from several nuclei including octavolateralis nuclei, facial lobes, motor nuclei and spinal sensory nucleus.

\subsection{Histology}

2.3.1. General Brain Histology (Fig.

2)

\subsection{1.Telencephalon}

The olfactory bulb formed from four layers which from the outside inwards were: the olfactory nerve fiber layer, the glomerular layer, the plexiform layer and the granule cell layer (Alonso et al., 1989). Some groups of large cell bodies were randomly distributed in the ventro-medial portion of the olfactory bulb, these neurons are thought to be ganglion cells of the terminal nerve and function in gonadotrophin releasing hormone synthesis in the gilthead seabream (Gothilf et al., 1996). The cerebrum consisted of a single layer in all teleosts (Ito and Yamamoto, 2009; Sharareh et 
al., 2013) but was lobulated in Epinephelus coioides (Sharareh et al., 2013).

\subsubsection{Diencephalon}

The diencephalon formed from, dorsal epithalamus which located under the optic tectum, and contains the pineal gland, the habenular ganglion and saccus dorsalis, or tela choroidia, which located dorsorostraly to the diencephalon. The thalamus, it was in the middle, situated under the third ventricle between the tegmentum and the hypothalamus. (Eastman and Lannoo, 2004).

The most posterior region of the diencephalon is the hypothalamus, which considered the main structural complex and formed from the inferior lobes and the infundibular region. As well as, specialized structures, including the pituitary gland and the saccus vasculosus (FRANCK, 2009; Groman, 1982). The saccus vasculosus located between the two caudal parts of the inferior lobes of the hypothalamus, beneath the pituitary gland (Sharareh et al., 2013).

\subsubsection{Mesencephalon}

The most obvious part of the midbrain is the optic lobe; it has six histologically distinct layers; the stratum marginale, stratum opticum, stratum fibroetgricialem, stratum album central, stratum griseum central, and stratum periventriculae (Eastman and Lannoo, 2001, 2004). Different types of neurons form each layer of the optic tectum. Therefore, the cell layers of the optic tectum can be divided into different functional layers (Northcutt, 2002). The torus longitudinalis (TL) ppeared late during brain development, it is located beside the optic tectum and was detected only in actinopterygian fishes; it consists of two longitudinal parts evaginates from the optic tectum toward the mesencephalic ventricle (Candal et al., 2006; Folgueira et al., 2010).

\subsubsection{Hindbrain}

The corpus cerebelli is the largest part of the brain in Pseudo-pimelodus bufonius fish (Abrahão et al., 2015). The cerebellum function in receiving the sensory inputs and transferring it toward the motor nuclei. The cerebellum (metencephalon) was composed of the corpus and the valvula cerebella (Lee and Bullock, 1984). The histological structure of the cerebellum gray matter was consisting of; outer molecular, Purkinje cell, and inner granular layers except in Eleginops maclovinus fish (Eastman and Lannoo, 2008). Also, the cerebellum was consisted of corpus cerebelli and valvula cerebella in Epinephelus coioides fish (Sharareh et al., 2013).

\subsubsection{Myelencephalon}

The myelencephalon principally composed of the medulla oblongata, as the stem of the brain, and the paired vagal lobes (Lagler et al., 1977). The medulla oblongata structure affected by feeding habits of the fish especially the facial, vagal and somatic sensory lobes (Sreekala et al., 2011). The vagal lobe composed of sensory layer, a fiber layer and a motor layer (Morita et al., 1983). In goldfish, the vagal lobe becomes well developed at the age of six months (Lamb and Kiyohara, 2005).

\subsubsection{Adult Neurogenesis in Teleosts (Fig. 3)}

The neural stem cells are those cells which can divide and differentiate into different kinds of neuronal cells (Gage, 2000; Temple, 2001; Weissman et al., 2001). It was observed that amphibians and fishes have the ability to regenerate their brain tissues even at adulthood (Grandel et al., 2006; Kizil et al., 2012; Zupanc, 2009; Zupanc, 2001).

The brain in fish have several sites containing neural stem cells so have the ability for adult neurogenesis more than mammals 
which their brain contain only few limited sites having this property. The optic tectum is one of the regions in fish brains which contain several proliferating cells.

There are many markers can be used for detecting cell proliferation like bromodeoxyuridine (BrdU), proliferating cell nuclear antigen (PCNA) and some others. The most famous stem cell markersin nervous tissue are Sox 2 gene, and Musashi homolog1 (MSI1) gene (Bravo and Macdonald-Bravo, 1987; Ferri et al., 2004; Ito et al., 2010; Kaneko et al., 2000).

The PCNA has several advantages including; it can be used for counting the mitotic figures, it can be detected in most stages of cell cycle as well as it can be detected in any kind of tissue without the need of previous treatment in living animals. However other proliferation markers like tritiated thymidine $(3 \mathrm{H}-\mathrm{T})$ or BrdU should be injected in living fish before their detection in tissue immunohistochemically as they incorporated with the DNA which may make them toxic in high doses (Møllgård and Schumacher, 1993). Basically, PCNA immunohistochemistry results are closely related with 3H-T or BrdU (Ekström et al., 2001; Mueller and Wullimann, 2002; Mueller and Wullimann, 2003; Wullimann and Knipp, 2000).

Also thymidine analogs (IdU and CldU) can be used as proliferation markers and have some advantagesthan using previously mentioned markers. In the Medaka the optic tectum was found to have non glial stem cells. The glial property of the cells can be detected by either brain lipid binding protein (BLBP) or glial fibrillary acidic protein (GFAP) (Alunni et al., 2010). In zebrafish the periventricular gray zone of the optic tectum was detected to be the main site of adult neurogenesis (Ito et al., 2010).

The PTEN gene can control the function of the stem cell (Bonaguidi et al., 2011). As its deletion, leads to frequent unstopped regeneration in the neural stem cells (Gregorian et al., 2009). It has been proven that nitric oxide factor can control proliferation and apoptosis in brain of sturgeon as it has been detected in the same sites of PCNA and TUNEL immunohistochemistry (Pushchina and Obukhov, 2012).

In zebrafish embryo, the peripheral midbrain layer (PML) was found to have many proliferating stem cells located beside the optic tectum and TS. Continuous proliferation and apoptosis in the PML was detected after making mutation in the cad gene (Recher et al., 2013a).

The lipid content in the CNS of fish is very high it comes in the secondstage in lipid content after adipose tissue and contains very essential fatty acids (Carrié et al., 2000; Innis, 2007; Spector, 2001). So supplementation with fish oil in mammals like rat was proven to have protective effect for brain tissue from many diseases like amyloidosis (Spector, 2001).

Another sites in the brain other than optic tectum was found to have proliferating stem cells like the cerebrum (Lindsey et al., 2012; Kaslin et al., 2009; Ganz et al., 2010). Also, the cerebellum has many proliferating stem cells (Kaslin et al., 2009; Wullimann et al., 2011). 
Brain anatomy and Histology in Teleosts (Review Article)

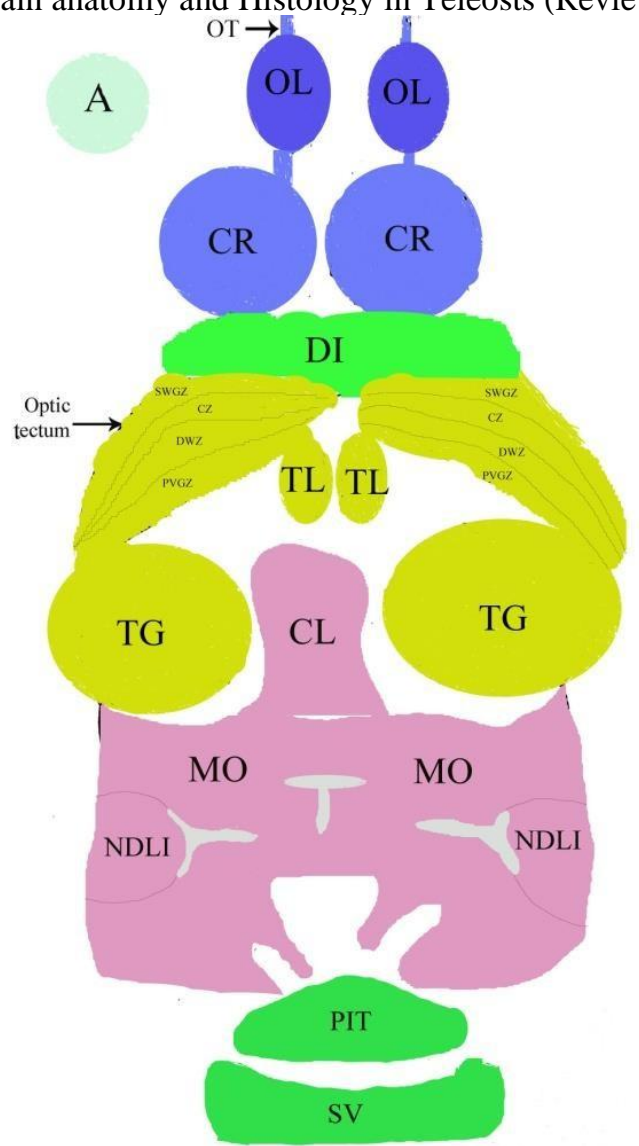

B
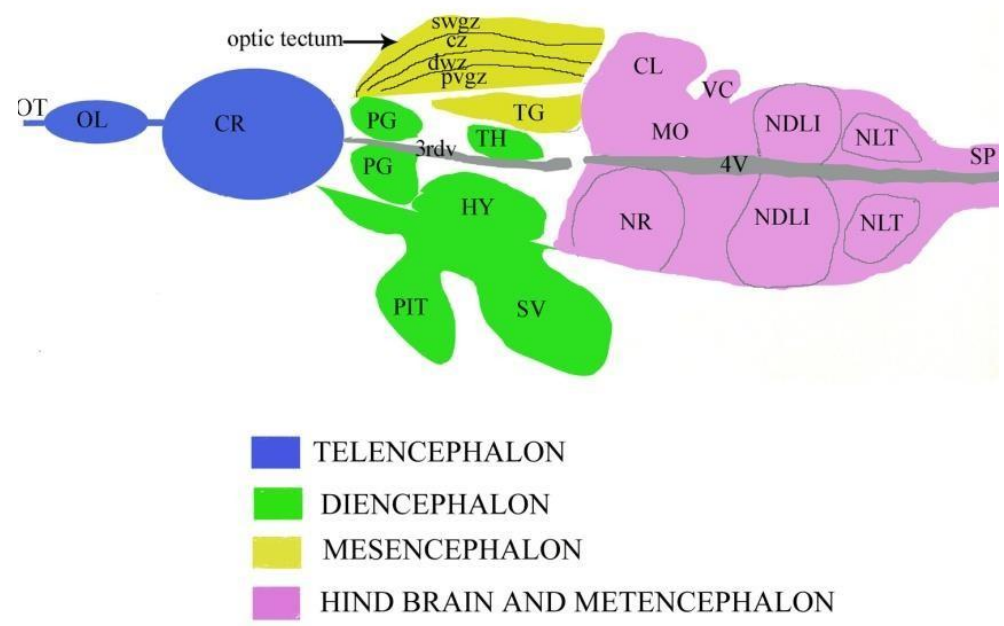

Fig. 1. The general anatomical description of brain in fish showing olfactory tract (OT), olfactory lobe (OL), cerebrum (CR), diencephalon (DI), layers of optic tectum; superficial white zone (SWZ), central zone (CZ), deep white zone (DWZ) and periventricular gray zone (PVGZ), torus longitudinalis (TL), optic tegmentum (TG), pineal gland $(\mathrm{PG})$, third ventricle $\left(3^{\text {rd }} \mathrm{v}\right)$, thalamus $(\mathrm{TH})$, hypothalamus (HY), pituitary gland (PIT), saccus vasculosus (SV), cerebellum (CL), valvula cerebelli (VC), medulla oblongata (MO), fourth ventricle (4V), nucleus recessus (NR), nucleus diffusus lobi inferioris (NDLI), nucleus lateralis tuberis (NLT) and spinal cord (SP). 


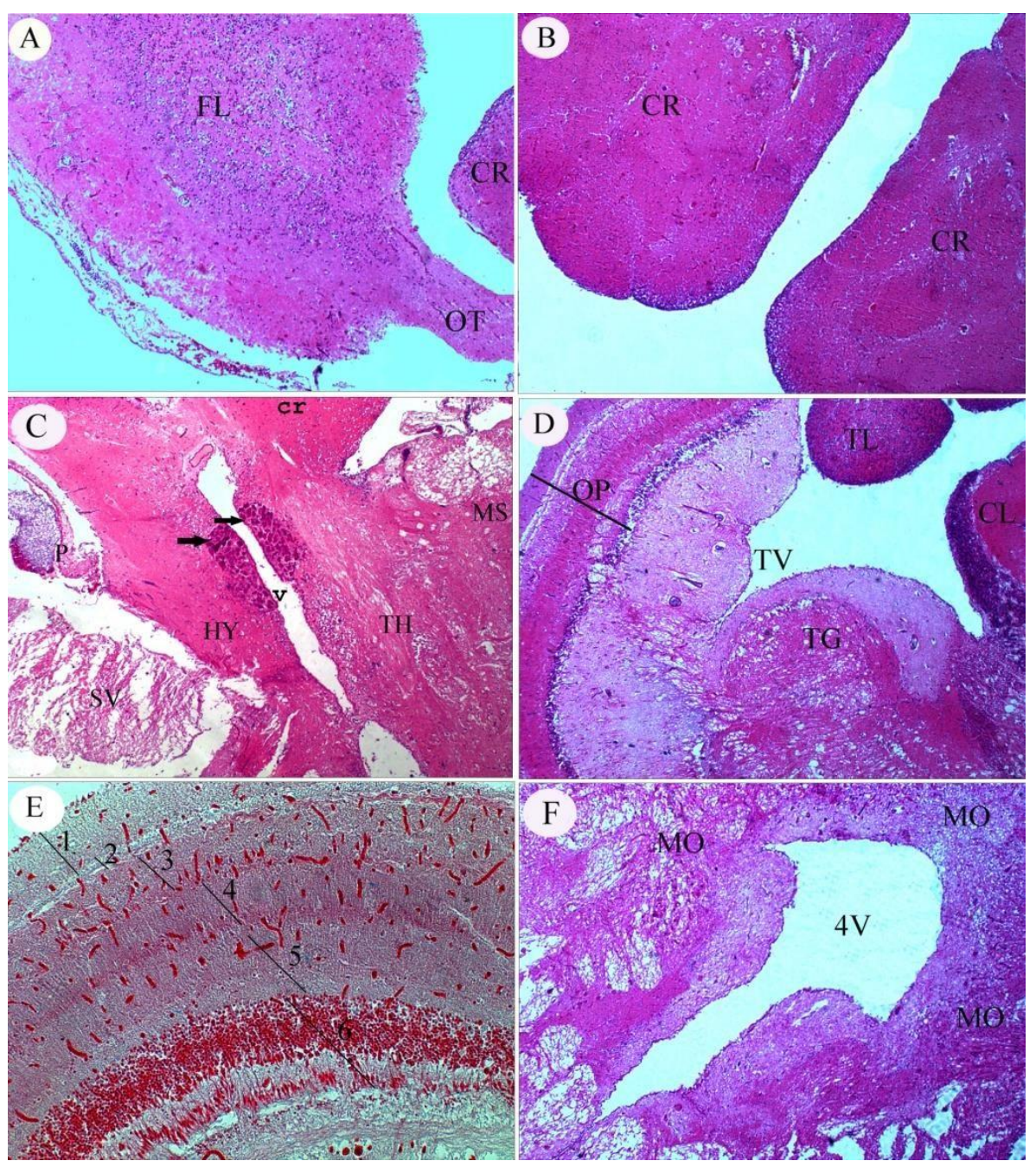

Fig. 2. The general histological structure of brain of fish. (A) The olfactory lobe (FL) is connected with the cerebrum (CR) via olfactory tract (OT) 100x. (B) The two cerebral hemispheres (CR) 50x. (C) Showing the diencephalon which is located caudal to cerebrum (cr) and in the left side of mesencephalon (MS). It formed from pineal gland (arrows) around third ventricle (v), thalamus (TH), hypothalamus (HY), pituitary gland (P) and saccus vasculosus (SV) 50x. (D) Showing optic tectum (OP), tectal ventricle (TV), optic tegmentum (TG), torus longitudinalis (TL) and cerebellum (CL) 50x. (E) High magnification of optic tectum which formed from (1) stratum marginale, (2) stratum opticum, (3) stratum fibroetgricialem, (4) stratum album central, (5) stratum griseum central and (6) stratum periventriculae 2oox. (F) The fourth ventricle (4V) and medulla oblongata (MO) 50x. These brain samples were taken from gray mullet fish, stained with hematoxylin and eosin stain except (E) stained with neutral red stain. Photos taken via zeiss light microscope. 


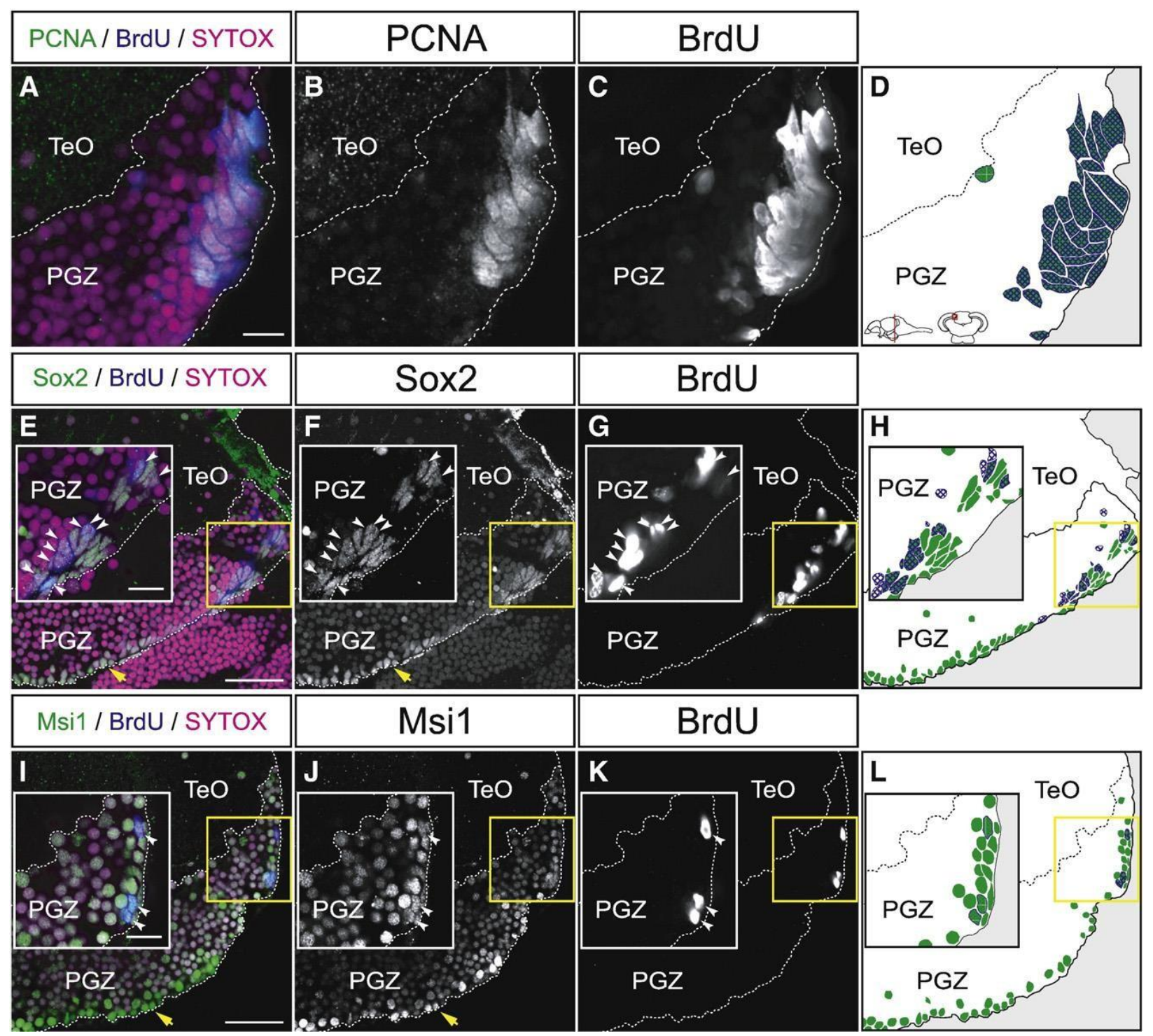

Fig. 3. Proliferating cells in the dorsomedial area of the PGZ express neural stem/progenitor cell markers. (A-L) Expression of PCNA (A-D), Sox 2 (E-H), and Msi1 (I-L) in the dorsomedial area of the PGZ of the adult zebrafish optic tectum (60 $\mu \mathrm{m}$ transverse sections, single planes, dorsal top). Proliferating cells are labeled with BrdU after $72 \mathrm{~h}$ of incubation. Insets in E-L show magnified views of the yellow-boxed areas. (A-D) Most PCNA-positive cells incorporate BrdU after 72 h of BrdU administration. (E-F) The majority of BrdU-positive proliferating cells (insets, arrowheads), and the cells that reside in the ventral edge of the PGZ (yellow arrows) express Sox2. (I-L) A subset of BrdU-positive cells (insets, arrowheads), and the cells that reside in the ventral edge of the PGZ (yellow arrows) express Msi1. CCe, corpus cerebelli; PGZ, periventricular gray zone; TeO, tectum opticum. Scale bars: $10 \mu \mathrm{m}$ in A, insets of E, I; $30 \mu \mathrm{m}$ in E, I. (Ito et al. 2010). 


\section{CONCLUSION}

The embryonic neural tube forms the several compartments of the brain and the spinal cord by the division of the neural stem cells. The hollow neural tube contains cerebrospinal fluid which secreted from ependymal cells lining it. This tube differentiates to form the ventricular system which formed from the olfactory ventricle and lateral ventricle present in the telencephalic hemispheres. The olfactory lobe is spherical or oval or pyriform in shape, its shape and size differ according to kind of fish, and it connected via olfactory tract to the olfactory mucosa and joined in the other side by olfactory tract to the cerebrum. The cerebrum histologically formed from a single layer in all teleosts and anatomically can be divided into dorsal and ventral parts. The epithalamus formed from the pineal gland, habenular ganglion and saccus dorsalis. The nucleus glomerulosus is the most visible part of the thalamus in histological slides of most kinds of fishes. The hypothalamus consists of the inferior lobes, infundibular region, saccus vasculosus and pituitary gland. In some types of fish which depend mainly on vision, the optic tectum is the most significant part of their brains, like rasterlliger brachysoma and gray mullet fishes. The torus longitudinalis (TL) which present only in action-pterygian fishes protrude from the optic tectum midline into the tectal ventricle.

The nucleus isthmi (NI) are located under the TS, cranial to the cerebellum and some fibersfrom the tectum surround it. It is well developed in fishes with high vision ability but also is found in blind cave fishes. However, it has not been found in elasmobranchs. The cerebellum is the most prominent structure in pseudo-pimelodus bufonis fish, sharks, and epinephelus coioides fish. It is formed from corpus cerebella and valvula cerebella. The medulla oblongata is also large in size; it composed from vagal and facial lobe which responsible for the taste sensation. It can be concluded that there are many fishes their brains are still not fully described like loaches, gray mullet and catfishes and many others.

Also, the mechanism of adult neurogenesis is not well understood in spite a lot of many recent research papers give significant results but still need further studies in it. We still need to do more comparison between fish and mammalian brain in relation to adult neurogenesis.

\section{Competing interests}

The authors declare that they have no competing interests.

\section{Acknowledgment}

The authors express great thanks for Dr. Mohamed Ayaad for his help in revision of English writing.

\section{REFERENCES:}

Abrahão, V.P., Shibatta, O.A., Abrahão, V.P., Shibatta, O.A., 2015. Gross morphology of the brain of Pseudopimelodus bufonius (Valenciennes, 1840) (Siluriformes: Pseudopimelodidae). Neotropical Ichthyology 13(2).

Alonso, J.R., Lara, J., Vecino, E., Coveñas, R., Aijón, J., 1989. Cell proliferation in the olfactory bulb of adult freshwater teleosts. Journal of Anatomy 163(4), 155-163.

Alunni, A., Hermel, J.M., Heuzé, A., Bourrat, F., Jamen, F., Joly, J.S., 2010. Evidence for neural stem cells in the medaka optic tectum proliferation

zones. Developmental Neurobiology 70(10), 693.

Bäuerle, A., Rahmann, H., 1993. Morphogenetic differentiation of the brain of the cichlid fish, Oreochromis mossambicus. Journal Für 
Hirnforschung 34(3), 375.

Bonaguidi, M.A., Wheeler, M.A., Shapiro, J.S., Stadel, R.P., Sun, G.J., Ming, G.L., Song, H., 2011. In vivo clonal analysis reveals self-renewing and multipotent adult neural stem cell characteristics. Cell 145(7), 1142-1155.

Bravo, R., Macdonald-Bravo, H., 1987. Existence of two populations of cyclin/proliferating cell nuclear antigen during the cell cycle: association with DNA replication sites. Journal of Cell Biology 105(4), 1549-1554.

Butler, A.B., 2011. BRAIN AND NERVOUS SYSTEM | Functional Morphology of the Brains of Ray-Finned Fishes. Encyclopedia of Fish Physiology, 3745.

Butler, A.B., Hodos, W., 2005. Comparative Vertebrate Neuroanatomy: Evolution and Adaptation, Second Edition.

Butler, A.B., Northcutt, R.G., 1993. The diencephalon of the pacific herring, Clupea harengus: Cytoarchitectonic analysis. Journal of Comparative Neurology 328(4), 527.

Candal, E., Anadón, R., Bourrat, F., Rodríguez- Moldes, I., 2006. Cell proliferation in the developing and adult hindbrain and midbrain of trout and medaka (teleosts): a segmental approach. Developmental Brain Research 160(2), 157-175.

Candal, E., Anadón, R., Bourrat, F., Rodríguezmoldes, I., 2005. Cell proliferation in the developing and adult hindbrain and midbrain of trout and medaka (teleosts): a segmental approach. Developmental Brain Research 160(2), 157-175.

Carrié, I., Clément, M., De, J.D., Francès, H., Bourre, J.M., 2000. Specific phospholipid fatty acid composition of brain regions in mice. Effects of $n-3$ polyunsaturated fatty acid deficiency and phospholipid supplementation. Journal of Lipid Research 41(3), 465.

Eastman, J.T., Lannoo, M.J., 2001. Anatomy and histology of the brain and sense organs of the Antarctic eel cod Muraenolepis microps (Gadiformes; Muraenolepididae). Journal of Morphology 250(1), 34-50.

Eastman, J.T., Lannoo, M.J., 2003. Anatomy and histology of the brain and sense organs of the antarctic plunderfish Dolloidraco longedorsalis (Perciformes: Notothenioidei: Artedidraconidae), with comments on the brain morphology of other artedidraconids and closely related harpagiferids. Journal of Morphology 255(3), 358.

Eastman, J.T., Lannoo, M.J., 2004. Brain and sense organ anatomy and histology in hemoglobinless Antarctic icefishes (Perciformes:

Notothenioidei
$\begin{aligned} & \text { : Channichthyidae). } \\ & \text { of Mournal }\end{aligned}$

Eastman, J.T., Lannoo, M.J., 2008. Brain and sense organ anatomy and histology of the Falkland Islands mullet, Eleginops maclovinus (Eleginopidae), the sister group of the Antarctic notothenioid fishes (Perciformes: Notothenioidei). Journal of Morphology 269(1), 84.

Ekström, P., Johnsson, C.M., Ohlin, L.M., 2001. Ventricular proliferation zones in the brain of an adult teleost fish and their relation to neuromeres and migration (secondary matrix) zones $\dagger$. Journal of Comparative Neurology 436(1), 92.

Ferri, A.L., Cavallaro, M.D., Di, C.A., Canta, A., Vezzani, A., Ottolenghi, S., Pandolfi, P.P., Sala, M., Debiasi, S., Nicolis, S.K., 2004. Sox2 deficiency causes neurodegeneration and impaired neurogenesis in the adult mouse brain. Development 131(15), 3805-3819.

Folgueira, M., Sueiro, C., Rodríguez-Moldes, I., Anadón, R., 2010. Organization of the torus longitudinalis in the rainbow trout (Oncorhynchus mykiss):

$$
\text { An }
$$

immunohistochemical study of the GABAergic system and a DiI tract-tracing study. Journal of 
Comparative Neurology 503(2), 348370.

FRANCK, 2009. ATLAS OF FISH HISTOLOGY. Crc Press.

Gage, F.H., 2000. Mammalian neural stem cells. Science 287(5457), 1433.

Ganz, J., Kaslin, J., Hochmann, S., Freudenreich, D., Brand, M., 2010. Heterogeneity and Fgf dependence of adult neural progenitors in the zebrafish telencephalon. Glia 58(11), 1345-1363.

González, A., Northcutt, R.G., 2011. BRAIN AND NERVOUS SYSTEM । Functional Morphology of the Brains of Sarcopterygian Fishes: Lungfishes and Latimeria. Encyclopedia of Fish Physiology, 46-55.

Gothilf, Y., Muñozcueto, J.A., Sagrillo, C.A., Selmanoff, M., Chen, T.T., Kah, O., Elizur, A., Zohar, Y., 1996. Three forms of gonadotropin-releasing hormone in a perciform fish (Sparus aurata): complementary deoxyribonucleic acid characterization and brain localization. Biology of Reproduction 55(3), 636-645.

Grandel, H., Kaslin, J., Ganz, J., Wenzel, I., Brand, M., 2006. Neural stem cells and neurogenesis in the adult zebrafish brain: origin, proliferation dynamics, migration and cell fate. Developmental Biology 295(1), 263.

Gregorian, C., Nakashima, J., Belle, J.L., Ohab, J., Kim, R., Liu, A., Smith, K.B., Groszer, M., Garcia, A.D., Sofroniew, M.V., 2009. Pten Deletion in Adult Neural Stem/Progenitor Cells Enhances Constitutive Neurogenesis. Journal of Neuroscience the Official Journal of the Society for Neuroscience 29(6), 1874.

Groman, D.B., 1982. Histology of the striped bass. Springer, Berlin.

Innis, S.M., 2007. Dietary (n-3) Fatty Acids and Brain Development. Journal of Nutrition 137(4), 855-859.

Ito, H., Yamamoto, N., 2009. Non-laminar cerebral cortex in teleost fishes? Biol Lett 5(1), 117-121.
Ito, Y., Tanaka, H., Okamoto, H., Ohshima, T., 2010. Characterization of neural stem cells and their progeny in the adult zebrafish optic tectum. Developmental Biology 342(1), 26-38.

Kaneko, Y., Sakakibara, S., Imai, T., Suzuki, A., Nakamura, Y., Sawamoto, K., Ogawa, Y., Toyama, Y., Miyata, T., Okano, H., 2000. Musashi1: An Evolutionally Conserved Marker for CNS Progenitor Cells Including Neural Stem Cells. Dev Neurosci 22(1-2), 139153.

Kaslin, J., Ganz, J., Geffarth, M., Grandel, H., Hans, S., Brand, M., 2009. Stem cells in the adult zebrafish cerebellum: initiation and maintenance of a novel stem cell niche. Journal of Neuroscience the Official Journal of the Society for Neuroscience 29(19), 6142.

Kizil, C., Kaslin, J., Kroehne, V., Brand, M., 2012. Adult neurogenesis and brain regeneration in zebrafish. Developmental Neurobiology 72(3), 429-461.

Lagler, K.F., Bardach, J.E., Miller, R.R., Passino, D.R.M., 1977. Ichthyology - 2. ed.

Lamb, C., Kiyohara, S., 2005. Development of the Vagal Taste System of Goldfish. Chemical Senses 30 Suppl 1(Supplement 1), i58.

Lee, L.T., Bullock, T.H., 1984. Sensory representation in the cerebellum of the catfish. Neuroscience 13(1), 157.

Lindsey, B.W., Darabie, A., Tropepe, V., 2012. The cellular composition of neurogenic periventricular zones in the adult zebrafish forebrain. Journal of Comparative Neurology 520(10), 2275.

Møllgård, K., Schumacher, U., 1993. Immunohistochemical assessment of cellular proliferation in the developing human CNS using formalin-fixed paraffin-embedded material. J Neurosci Methods 46(3), 191-196.

Morita, Y., Murakami, T., Ito, H., 1983. Cytoarchitecture and topographic projections of the gustatory centers in a 
teleost, Carassius carassius. Journal of Comparative Neurology 218(4), 378.

Mueller, T., Wullimann, M.F., 2002. BrdU-, neuroD ( nrd )- and Hu-studies reveal unusual non-ventricular neurogenesis in the postembryonic zebrafish forebrain. Mechanisms of Development 117(1), 123-135.

Mueller, T., Wullimann, M.F., 2003. Anatomy of neurogenesis in the early zebrafish brain. Developmental Brain Research Nieuwenhuys, R., 1998. Chondrostean

Fishes. 701-757.

Nieuwenhuys, R., 2011. The development and general morphology of the telencephalon of actinopterygian fishes: synopsis, documentation and commentary. Brain Structure \& Function 215(3-4), 141-157.

Northcutt, R.G., 2002. Understanding Vertebrate Brain Evolution. Integrative \& Comparative Biology 42(4), 743-756.

Northcutt, R.G., Jr, M.R.B., 1980. New Observations on the Organization and Evolution of the Telencephalon of Actinopterygian Fishes. Springer US.

Puelles, L., Rubenstein, J.L., 1993. Expression patterns of homeobox and other putative regulatory genes in the embryonic mouse forebrain suggest a neuromeric organization. Trends in Neurosciences 16(11), 472-479.

Pushchina, E.V., Obukhov, D.K., 2012. Nitric oxide-factor, which

\section{regulates}

proliferation and apoptosis in the adult brain of amur sturgeon. Advances in Bioscience \& Biotechnology 03(6), 788- 804.

Recher, G., Jouralet, J., Brombin, A., Heuzé, A., Mugniery, E., Hermel, J.M., Desnoulez, S., Savy, T., Herbomel, P., Bourrat, F., 2013a. Zebrafish midbrain slow- amplifying progenitors exhibit high levels of transcripts for nucleotide and ribosome biogenesis. Development 140(24), 4860.
140(1), 137-155.

Mueller, T., Wullimann, M.F., 2016. Chapter 1 - Vertebrate Central Nervous System Development : Introduction. Atlas of Early Zebrafish Brain Development, 1, 3-26.

Neary, T.J., Northcutt, R.G., 2010. Nuclear organization of the bullfrog diencephalon. Journal of Comparative Neurology 213(3), 262-278.

Recher, G., Jouralet, J., Brombin, A., Mugniery, E., Hermel, J.M., Desnoulez, S., Savy, T., Herbomel, P., Bourrat, F., Jamen, F., 2013 b. Zebrafish midbrain slow- amplifying progenitors exhibit high levels of transcripts for nucleotide and ribosome biogenesis. Development 140(24), 4860-4869.

Redzic, Z.B., Preston, J.E., Duncan, J.A., Chodobski, A., SzmydyngerChodobska, J., 2005. The choroid plexus- cerebrospinal fluid system: from development to aging. Current Topics in Developmental Biology 71(71), 1-52.

Rosa, A.C., Rosa, A.C., 2014. Miniaturization in Otothyris Myers, 1927 (Loricariidae: Hypoptopomatinae).

Neotro

pical Ichthyology 12(1), 53-60.

Rupp, B., Northcutt, R.G., 1998. The diencephalon and pretectum of the white sturgeon (Acipenser transmontanus): a cytoarchitectonic study. Brain Behavior \& Evolution 51(5), 239-262.

Sharareh, S., Alireza, S., Bita, A., Ahmad, S., Rahim, A., 2013. BRAIN ANATOMY AND HISTOLOGY OF ORANGE SPOTTED GROUPER (EPINEPHELUS COIOIDES). Journal of the Persian Gulf 4(14), 1-13.

Spector, A.A., 2001. Plasma free fatty acid and lipoproteins as sources of polyunsaturated fatty acid for the 
brain. Journal of Molecular Neuroscience 16(2- 3), 159-165.

Sprague, J., Doerry, E., Douglas, S., Westerfield, M., 2001. The Zebrafish Information Network (ZFIN): a resource for genetic, genomic and developmental research. Nucleic Acids Research 29(1), 87-90.

Sreekala, S., Raj, M.V., Sherly, P.S., 2011. Correlation between medulla oblongata and feeding habits in two teleosts. Indian Journal of Science \& Technology 4(12).

Tavighi, S.H., Saadatfar, Z., Shojaei, B., Rassouli, M.B., 2015. Brain ventricle development in $\mathrm{H}$. huso (Beluga sturgeon) larvae. Anatomical Science International 91(4), 1-8.

Temple, S., 2001. The development of neural stem cells. Nature 414(6859), 112117.

Toyoda, J., Uematsu, K., 1994. Brain morphogenesis of the red sea bream, Pagrus major (teleostei). Brain Behavior \& Evolution 44(6), 324337.

Weissman, I.L., Anderson, D.J., Gage, F., 2001. Stem and progenitor cells: origins, phenotypes, lineage commitments, and transdifferentiations. Annual Review of Cell \& Developmental Biology 17(17), 387-403.

Wullimann, M.F., Knipp, S., 2000. Proliferation pattern changes in the zebrafish brain from embryonic through early postembryonic stages. Anat Embryol 202(5), 385-400.

Wullimann, M.F., Mueller, T., Distel, M., Babaryka, A., Grothe, B., Köster, R.W., 2011. The Long Adventurous Journey of Rhombic Lip Cells in Jawed Vertebrates: A Comparative Developmental Analysis. Frontiers in Neuroanatomy 5(27), 27.

Zupanc, G.K., 2009. Towards brain repair: Insights from teleost fish. Seminars in Cell \& Developmental Biology 20(6),
683-690.

Zupanc, G.K.H., 2001. Adult Neurogenesis and Neuronal Regeneration in the Central Nervous System of Teleost Fish. Brain Behavior \& Evolution 58(5), 250-275. 